\title{
Modelling the NO emissions from wildfires at the source level
}

\author{
Y. Pérez-Ramirez ${ }^{1}$, P.-A. Santoni ${ }^{1}$, and N. Darabiha ${ }^{2}$ \\ ${ }^{1}$ UMR CNRS 6134 - SPE, University of Corsica, Corte, France \\ ${ }^{2}$ Laboratoire EM2C, CNRS UPR 288, Ecole Centrale Paris, Chatenay Malabry, France \\ Correspondence to: Y. Pérez-Ramirez (perez-ramirez@univ-corse.fr)
}

Received: 30 September 2013 - Published in Nat. Hazards Earth Syst. Sci. Discuss.: 4 December 2013

Revised: 19 October 2013 - Accepted: 8 April 2014 - Published: 20 May 2014

\begin{abstract}
There is a growing interest to characterize fire plumes in order to control air quality during wildfire episodes and to estimate the carbon and ozone balance of fire emissions. A numerical approach has been used to study the mechanisms of NO formation at the source level in wildfires given that $\mathrm{NO}$ plays an important role in the formation of ground-level ozone. The major reaction mechanisms involved in NO chemistry have been identified using reaction path analysis. Accordingly, a two-step global kinetic scheme in the gas phase has been proposed herein to account for the volatile fuel-bound nitrogen (fuel-N) conversion to NO, considering that the volatile fraction of fuel- $\mathrm{N}$ is released as $\mathrm{NH}_{3}$. Data from simulations using the perfectly stirred reactor (PSR) code from CHEMKIN-II package with a detailed kinetic mechanism (GDF-Kin ${ }^{\circledR} 3.0$ ) have been used to calibrate and evaluate the global model under typical wildfire conditions in terms of the composition of the degradation gases of vegetation, the equivalence ratio, the range of temperatures and the residence time.
\end{abstract}

\section{Introduction}

Wildfires are a major emission source of $\mathrm{CO}, \mathrm{CO}_{2}, \mathrm{NO}_{\mathrm{x}}$ $\left(\mathrm{NO}+\mathrm{NO}_{2}\right)$ volatile organic compounds (VOCs) and particulates to the atmosphere (Barboni et al., 2010), which in turn can form secondary pollutants with implications at lo$\mathrm{cal} /$ regional scale (i.e. air quality, human health) or at global scale (i.e. climate dynamics). This is the case for $\mathrm{NO}_{\mathrm{x}}$, which are major contributors of photochemical smog and thus of ground-level ozone (Grewe et al., 2012).

In the context of the present climate change scenario, there is a growing interest to characterize fire plumes in order to control air quality during wildfire episodes and to estimate the carbon and ozone balance of fire emissions (Miranda, 2004; Strada et al., 2012).

Atmospheric emissions from wildfires have generally been assessed using bottom-up estimates which require explicit knowledge on fire behaviour, area burned, fuel consumption, fuel characteristics and pollutant-specific emission factors at the source level. Despite the recent improvements, these methods entail errors and uncertainties in each step (Ottomar et al., 2009), particularly concerning the emission factors. In this regard, in the literature average values of emission factors can be found for a given pollutant and vegetation structure. Nevertheless, there are wide variations in the values presented for the same type of vegetation; this is especially remarkable in the case of certain pollutants such as $\mathrm{NO}_{\mathrm{x}}(\mathrm{Me}-$ bust et al., 2011). This variability underlines the generally limited understanding of the combustion processes of vegetation (Sullivan and Ball, 2012).

Average emission factors for a certain type of vegetation structure are useful to generate overall emission factors; however they do not reflect the spatial and temporal variability of wildfires. The wide range in observed emissions from a single fire reflects the variable and changing combustion conditions (Jaffe and Wigder, 2012). Thus, studies focused on understanding instantaneous emissions from wildfires require more detailed information on the emissions of pollutants at the source level and thus on the combustion processes of vegetation.

Likewise, the analysis of combustion processes is also decisive for wildfires' behaviour modelling. In fact, the rate and amount of energy released from the fuel and thus the amount of energy to be transferred to surrounding unburned fuel, which may induce its subsequent ignition, are derived from the fundamental chemistry of the fuel and its combustion (Sullivan, 2009). 


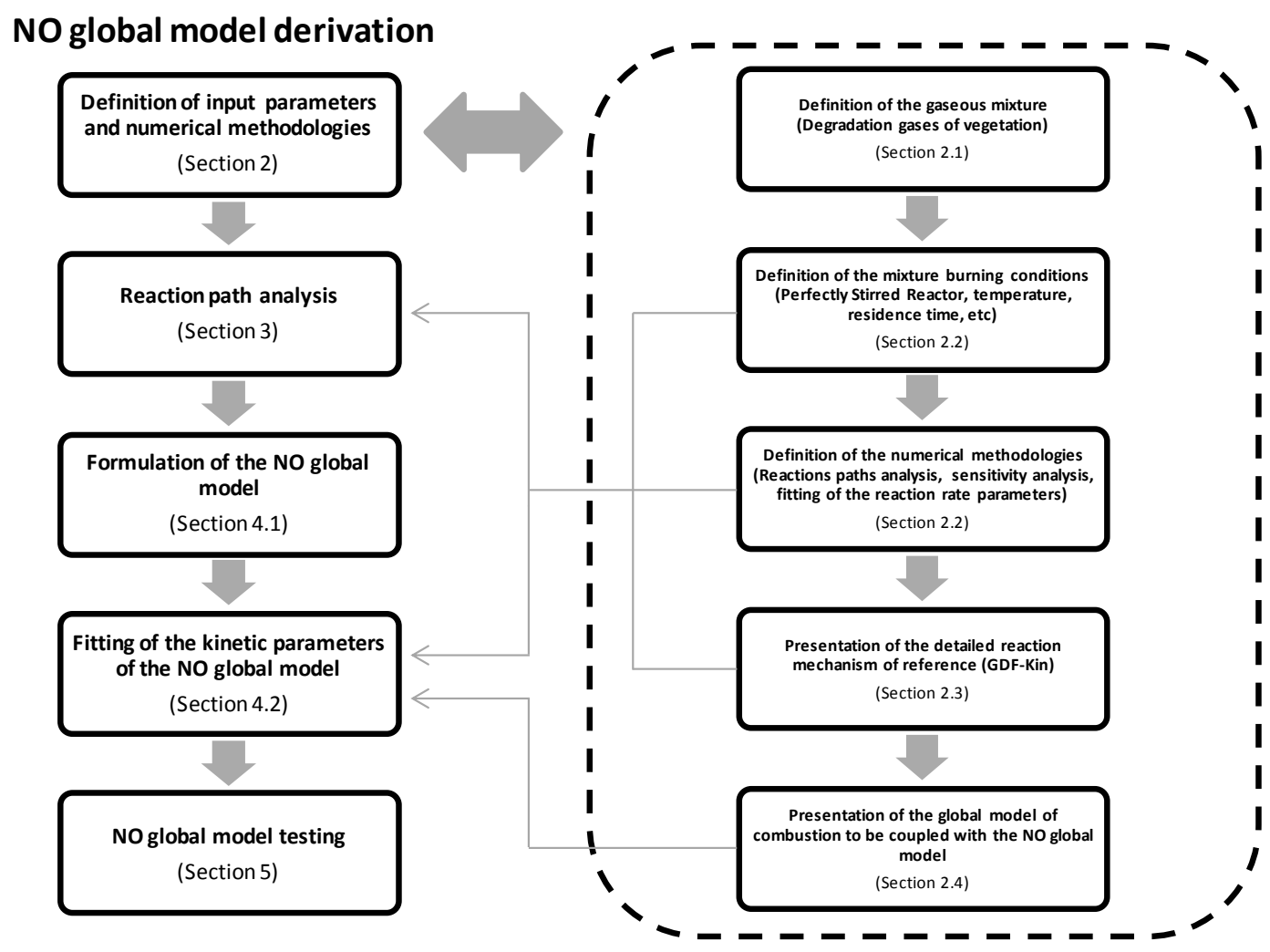

Figure 1. Flowchart of the workflow and the methodology steps.

However, the use of detailed kinetic mechanisms, which involve a large number of chemical species and reactions, results in an unfeasible solution to predict fire spread and its associated pollutant emissions at the landscape scale. The number of chemical species and reactions included in a kinetic mechanism must be a balance of the competing needs of accuracy and simplicity to attain the computational time requirements. In this regard, global kinetic mechanisms attempt to simplify the detailed chemistry in order to predict important physical quantities, such as the concentration profile of the principal species or the rate of energy released.

The aim of this work is to improve the current knowledge on the combustion processes responsible for the emissions of pollutants of wildland fires at the source level by focusing on NO modelling. A two-step global oxidation scheme has been developed to account for the NO emissions in wildland fire conditions. The major reaction mechanisms involved in NO chemistry have been identified using reaction path analysis through reaction rate analysis and sensitivity analysis with a detailed kinetic mechanism (GDF-Kin ${ }^{\circledR}$ 3.0). The kinetic parameters of the global model have been determined using numerical data obtained with GDF-Kin ${ }^{\circledR} 3.0$ in a perfectly stirred reactor environment under typical wildfire conditions in terms of the inlet mixture composition, equivalence ratio and range of temperatures. Moreover, the model has been tested in conditions other than the calibration conditions in terms of the residence time.

Section 2 is devoted to the procedures concerning the study of NO chemistry and the calibration of the global model. Next, Sect. 3 is focused on the reaction path analysis through rate-of-production and sensitivity analyses. Sections 4 and 5 concern the derivation of the global model and the evaluation of the performances of the model in comparison with experimental data available in the literature and the numerical results obtained from a detailed kinetic mechanism (GDF-Kin ${ }^{\circledR} 3.0$ ) for different residence times. Finally, conclusions are summarized in Sect. 6.

\section{Materials and methods}

The following subsections describe the procedures for the derivation of the global NO model and its calibration and testing, as summarized in Fig. 1.

\subsection{Degradation gases of vegetation}

The use of global kinetic mechanisms entails the simplification of not only combustion kinetics but also fuel chemistry since all the species present in the gases released from the thermal degradation of vegetation cannot be taken into account. Often, for fire modelling purposes it is generally 
assumed that the degradation gases of vegetation are composed only by the chemical species present in larger amounts, i.e. $\mathrm{CO}$ and $\mathrm{CO}_{2}$ (Morvan and Dupuy, 2004). However, the simplification of the composition of the degradation gas mixture can lead to a loss of accuracy of the model predictions (Tihay et al., 2009a) and also the estimation of pollutant emissions as NO.

Several mechanisms can lead to the formation of NO (Glarborg, 2007). These mechanisms imply either the fixation of the molecular nitrogen contained in the combustion air (i.e. thermal, prompt, $\mathrm{N}_{2} \mathrm{O}$ and $\mathrm{NNH}$ pathways) or the oxidation of organic nitrogen chemically bound in the fuel (i.e. fuel-N pathway).

In the combustion of vegetation, the main path for $\mathrm{NO}$ formation is the fuel-N route (Salzmann and Nussbaumer, 2001; Rogaume et al., 2006; Glarborg, 2007). Vegetation contains small amounts of fuel-bound nitrogen; typical values range from 0.1 to $3.5 \%$ weight (Glarborg, 2007). When vegetation is exposed to a thermal source during the degradation, the parent fuel- $\mathrm{N}$ is partly released as volatile- $\mathrm{N}$ and partly transformed in char- $\mathrm{N}$. The volatile fraction is essentially composed by $\mathrm{HCN}, \mathrm{NH}_{3}, \mathrm{HNCO}$ and tars. Some authors have reported that $\mathrm{NH}_{3}$ is the main volatile- $\mathrm{N}$ species during biomass pyrolysis and that the release of $\mathrm{HCN}$ from the fuel was always almost negligible (Weissinger et al., 2004; Zhou et al., 2006). Nevertheless, the extent of conversion of fuel-N to NO is nearly independent of the identity of the model compound ( $\mathrm{HCN}, \mathrm{NH}_{3}$, etc.), but it is strongly dependant on the local combustion environment (temperature and stoichiometry) and on the initial level of nitrogen compound in the fuelair mixture (Sullivan et al., 2002).

The fuel-N mechanism is more complex than the other NO formation paths; even though the overall mechanism is fairly well established, details are still under investigation especially for heterogeneous mixtures due to the sensitization effects between species, such as methane or carbon oxides to nitrogen oxides (Faravelli et al., 2003; Glarborg, 2007; Mendiara and Glarborg, 2009). This is the case for the gases released from the thermal degradation of vegetation, which form a mixture containing a great variety of chemical species. Indeed the complexity of the combustion processes involving the degradation gases of vegetation relies on their composition and the wide range of conditions occurring in a wildfire.

To our knowledge, there are no studies in the literature concerning the composition of the degradation gases of forest fuels quantifying the volatile fraction of fuel-N. However, Leroy et al. (2008) carried out a detailed study of the oxidation of a $\mathrm{CH}_{4} / \mathrm{CO} / \mathrm{CO}_{2}$ gas mixture representative of the thermal degradation of Pinus pinaster needles, which is a natural species frequently used in wildfires experimentation since it is a widespread species characteristic of the forests in the Mediterranean Basin. This gaseous mixture was obtained using a tubular furnace allowing the pyrolysis of Pinus pinaster needles under an inert atmosphere (Tihay et al., 2009b). Experiments were conducted in the temperature range $563-723 \mathrm{~K}$, which corresponds to the maximum yields of gas released observed in thermogravimetric analysis (TGA) on thermal degradation of forest fuels.

So we considered the gaseous mixture proposed by Leroy et al. (2008) but doped with the corresponding volatile-N fraction released from the thermal degradation of the pine needles. For this, we assumed that volatile-N was only composed by $\mathrm{NH}_{3}$ because, although the nitrogen species $\left(\mathrm{NH}_{3}\right.$, $\mathrm{HCN}$ ) initially follow different oxidation paths, the steps that determine the selectivity towards $\mathrm{NO}$ and $\mathrm{N}_{2}$ are essentially the same (Sullivan et al., 2002). Then, we considered that the volatile- $\mathrm{N}$ fraction corresponded to $80 \%$ of the amount of fuel-bound nitrogen (Brink et al., 2001), which was obtained from an elementary analysis of a sample of Pinus pinaster needles. The resulting mixture composition for the degradation gases of Pinus pinaster needles was $0.23 \%$ of $\mathrm{NH}_{3}$, $30.43 \%$ of $\mathrm{CO}, 50.98 \%$ of $\mathrm{CO}_{2}$, and $18.36 \%$ of $\mathrm{CH}_{4}$ (mole fractions).

\subsection{Numerical approach}

Calculations were carried out using the perfectly stirred reactor (PSR) code (Glarborg et al., 1986) from CHEMKIN-II package (Kee et al., 1989), which provides predictions of the steady-state temperature and species composition in a PSR. In a PSR the rate of conversion from reactants to products is kinetically controlled, and therefore combustion is only characterized by the residence time, the mixture composition and the temperature. Thus, the PSR configuration allows testing the global model at different temperatures and fuel equivalence ratios.

The global model formulation was derived from the full reaction mechanism through sensitivity analysis and rateof-production analysis of PSR calculations covering the range of interest for the gaseous mixture previously detailed (Sect. 2.1). Only the reactions concerning species with a rate of production greater than $5 \%$ and the reactions with sensibility greater than $5 \%$ were considered.

Regarding the calibration of the reaction rate expressions, a regression analysis was performed whereby the global parameters were adjusted by optimizing the match between the main species (i.e. $\mathrm{NO}$ and $\mathrm{NH}_{3}$ ) concentration profiles (as a function of the temperature and fuel equivalence ratio) obtained by the global model and the reference detailed mechanism (GDF-Kin ${ }^{\circledR} 3.0$ ). For this, the NO global model was coupled to a five-step global kinetic mechanism (PérezRamirez et al., 2012) in order to take into account the combustion of the $\mathrm{CH}_{4} / \mathrm{CO}$ present in the degradation gases of vegetation.

Simulations for the sensitivity analysis, reaction path analysis and the calibration of the model were performed at atmospheric pressure and at a constant residence time, for temperatures ranging between 773 and $1273 \mathrm{~K}$ (stepping $50 \mathrm{~K}$ ) and fuel equivalence ratios between 0.6 and 1.4. Moreover, 
reactants were diluted in argon (dilution factor 9.2) to avoid temperature rise in the reactor.

The residence time was set at $1.3 \mathrm{~s}$. This value was proposed by Jallais (2001) as an optimum value of time for controlling species to build up in a PSR of the same volume. In addition, this value is in accordance with the recommendations of David and Matras (1975) to assure a homogeneous distribution of species in PSR devices.

In order to test the model in conditions other than the calibration conditions, the model was evaluated for another residence time. In this case, the residence time was set at $0.6 \mathrm{~s}$. This value has been obtained from measurements performed at landscape scale in experimental fires across shrubland fuels (Santoni et al., 2006), and it corresponds to the average transit time of the degradation gases through the flame, i.e. from the base to the tip of the flame (Santoni, 2008). It is worth noting that the residence time for PSR calculations is not equivalent to the residence time of the flame, which is defined as the average time that the flame stays in a certain position, and it is thus related to the rate of spread.

\subsection{Reference detailed kinetic mechanism}

To our knowledge, there are no experimental data in the literature concerning the $\mathrm{NO}$ formation in PSR devices for $\mathrm{CH}_{4} / \mathrm{CO} / \mathrm{CO}_{2} / \mathrm{NH}_{3}$ gas mixtures in the conditions of this study. Indeed, experimental data available in the literature are very limited and concern gas mixtures of $\mathrm{CH}_{4}$ (Bartok et al., 1972; Duterque et al., 1981), $\mathrm{CH}_{4} / \mathrm{C}_{2} \mathrm{H}_{6}$ (Dagaut et al., 1998) or other hydrocarbons such as $\mathrm{C}_{3} \mathrm{H}_{8}, \mathrm{C}_{6} \mathrm{H}_{6}$ and $\mathrm{C}_{8} \mathrm{H}_{18}$ (Duterque et al., 1981) doped with different nitrogen compounds (e.g. $\mathrm{NH}_{3}, \mathrm{NO}, \mathrm{HCN}$, etc.). The experimental conditions differ depending on the work, and only the experiments performed by Dagaut et al. (1998) are closer to the conditions encountered in the combustion of vegetation in terms of temperature and fuel equivalence ratio. In this regard, Dagaut et al. (1998) carried out the experiments at temperatures ranging from 1100 to $1500 \mathrm{~K}$ and for fuel equivalence ratios in the range of 0.75-2.5. Dagaut et al. (1998) developed a detailed chemical kinetic model based on these experiments.

Thus, due to the lack of experimental data, the kinetic parameters of the reaction rate equations were fitted according to numerical results obtained with the detailed kinetic mechanism GDF-Kin ${ }^{\circledR} 3.0$ (El Bakali et al., 2006). This mechanism developed for the oxidation of natural gas takes into account the major and the minor alkanes present in the natural gas. Moreover, it incorporates the chemistry of nitrogen oxides from the mechanism developed by Dagaut et al. (1998).

Even though GDF-Kin ${ }^{\circledR} 3.0$ has not been specifically developed for the gas-phase combustion processes of vegetation, it has proven its performance for different test environments (e.g. shock tubes and jet-stirred reactors, premixed flames) and in various conditions of temperature, pressure and equivalence ratio (El Bakali et al., 2004, 2006).

\subsection{Global kinetic mechanism for the combustion of $\mathrm{CH}_{4} / \mathrm{CO}$}

The NO global model was implemented in conjunction with a five-step global mechanism (Pérez-Ramirez et al., 2012) to model the combustion of the $\mathrm{CH}_{4} / \mathrm{CO}$ present in the degradation gases of vegetation. This mechanism was developed for the conditions encountered in a wildfire scenario, and it was calibrated by using the experimental data obtained by Leroy et al. (2008) in a perfectly stirred reactor.

The first Reaction (R1) of this mechanism describes the breakdown of methane to an intermediate species, the methyl radical. The second and third reactions - Reactions (R2) and (R3) - describe the subsequent oxidation of the intermediate species, the methyl radical and the formaldehyde, to carbon monoxide. And the fourth and fifth steps (Reactions R4 and R5) correspond, respectively, to the oxidation of hydrogen and carbon monoxide.

$\mathrm{CH}_{4} \Rightarrow \mathrm{CH}_{3}+\frac{1}{2} \mathrm{H}_{2}$

$\mathrm{CH}_{3}+\frac{1}{2} \mathrm{O}_{2} \Rightarrow \mathrm{CH}_{2} \mathrm{O}+\frac{1}{2} \mathrm{H}_{2}$

$\mathrm{CH}_{2} \mathrm{O}+\frac{1}{2} \mathrm{O}_{2} \Rightarrow \mathrm{CO}+\mathrm{H}_{2} \mathrm{O}$

$\mathrm{H}_{2}+\frac{1}{2} \mathrm{O}_{2} \Leftrightarrow \mathrm{H}_{2} \mathrm{O}$

$\mathrm{CO}+\frac{1}{2} \mathrm{O}_{2} \Leftrightarrow \mathrm{CO}_{2}$

The reaction rate parameters of the $\mathrm{CH}_{4} / \mathrm{CO}$ global model are listed in Table 1.

\section{Reaction analysis}

\subsection{Combustion of $\mathrm{CH}_{4} / \mathrm{CO} / \mathrm{CO}_{2}$ mixture}

The oxidation paths of $\mathrm{CH}_{4} / \mathrm{CO} / \mathrm{CO}_{2}$ mixture are similar to the oxidation paths of methane as identified by Leroy et al. (2008). Two pathways for the oxidation of methane can be established (Fig. 2). The first one is direct oxidation to $\mathrm{CH}_{3}$, which subsequently oxidizes to $\mathrm{CH}_{3} \mathrm{O}$ and $\mathrm{CH}_{2} \mathrm{O}$. The second path is oxidation to $\mathrm{CH}_{3}$ followed by the recombination of $\mathrm{CH}_{3}$ molecules to the formation of $\mathrm{C}_{2}$ hydrocarbons. The selectivity to one or the other pathway is given by the fuel equivalence ratio. In fuel-rich conditions the formation of $\mathrm{C}_{2}$ hydrocarbons will be favoured, whereas in fuel-lean conditions the direct oxidation will be preferential. Consequently, a different behaviour would also be expected for the oxidation of $\mathrm{NH}_{3}$ and thus the $\mathrm{NO}$ chemistry depending on the conditions in terms of the fuel equivalence ratio, as also pointed out in the literature (Sullivan et al., 2002). 
Table 1. Reaction rate equations and parameters of the global kinetic mechanism ( $\varphi$ : equivalence ratio; units $\dot{\omega}: \mathrm{molcm}^{-3} \mathrm{~s}^{-1}, E: \mathrm{cal} \mathrm{mol}^{-1}$, $k$ : consistent units) (Pérez-Ramirez et al., 2012).

\begin{tabular}{ll}
\hline Reaction rate equation & Parameters \\
\hline$\dot{\omega}_{\mathrm{R} 1}=k_{\{\mathrm{R} 1\}}\left[\mathrm{CH}_{4}\right]^{-0.33}\left[\mathrm{O}_{2}\right]^{1.0}\left(\left[\mathrm{CH}_{3}\right]+\left[\mathrm{CH}_{2} \mathrm{O}\right]\right)^{0.85} \exp \left[-\frac{E_{\{\mathrm{R} 1\}}}{R T}\right]$ & $k_{\{\mathrm{R} 1\}}=\exp (27.85+0.25 \varphi)$ \\
$\dot{\omega}_{\mathrm{R} 2}=k_{\{\mathrm{R} 2\}}\left[\mathrm{CH}_{3}\right]^{0.94}\left[\mathrm{O}_{2}\right]^{0.66} \exp \left[-\frac{E_{\{\mathrm{R} 2\}}}{R T}\right]$ & $E_{\{\mathrm{R} 1\}}=41670$ \\
$\dot{\omega}_{\mathrm{R} 3}=k_{\{\mathrm{R} 3\}}\left[\mathrm{CH}_{2} \mathrm{O}\right]^{1.11}\left[\mathrm{O}_{2}\right]^{0.38} \exp \left[-\frac{E_{\{\mathrm{R} 3\}}}{R T}\right]$ & $E_{\{\mathrm{R} 2\}}=36002$ \\
$\dot{\omega}_{\mathrm{R} 4 f}=k_{\{\mathrm{R} 4 f\}}\left[\mathrm{H}_{2}\right]^{1.00}\left[\mathrm{O}_{2}\right]^{0.50} \exp \left[-\frac{E_{\{\mathrm{R} 4 f\}}}{R T}\right]$ & $k_{\{\mathrm{R} 3\}}=1.06 \times 10^{13}$ \\
$\dot{\omega}_{\mathrm{R} 4 r}=k_{\{\mathrm{R} 4 r\}}\left[\mathrm{H}_{2} \mathrm{O}\right]^{1.00} \exp \left[-\frac{\left.E_{\{\mathrm{R} 4 r\}}\right]}{R T}\right]$ & $E_{\{\mathrm{R} 3\}}=41976$ \\
$\dot{\omega}_{\mathrm{R} 5 f}=k_{\{\mathrm{R} 5 f\}}[\mathrm{CO}]^{1.00}\left[\mathrm{O}_{2}\right]^{0.50} \exp \left[-\frac{E_{\{\mathrm{R} 5 f\}}}{R T}\right]$ & $k_{\{\mathrm{R} 4 f\}}=2.90 \times 10^{13}$ \\
$\dot{\omega}_{\mathrm{R} 5 r}=k_{\{\mathrm{R} 5 r\}}\left[\mathrm{CO}_{2}\right]^{1.00} \exp \left[-\frac{\left.E_{\{\mathrm{R} 5 r\}}\right]}{R T}\right]$ & $k_{\{\mathrm{R} 4 f\}\}}=3.93 \times 10^{12}$ \\
& $E_{\{\mathrm{R} 4 r\}}=106058$ \\
& $k_{\{\mathrm{R} 5 f\}}=\exp (33.40-3.50 \varphi)$ \\
& $E_{\{\mathrm{R} 5 f\}}=47773$ \\
& $k_{\{\mathrm{R} 5 r\}}=2.90 \times 10^{13}$ \\
& $E_{\{\mathrm{R} 5 r\}}=112042$ \\
\hline
\end{tabular}

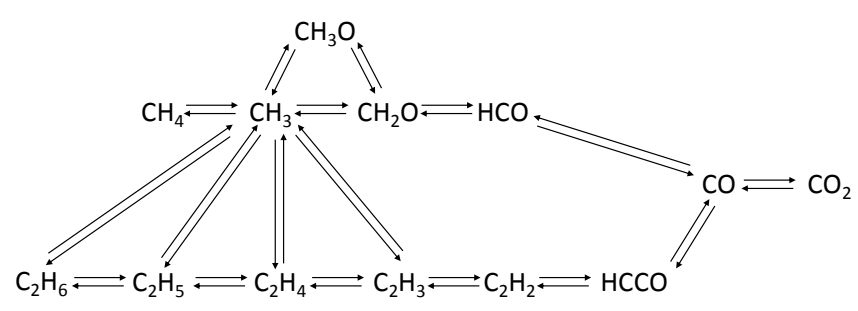

Figure 2. Reaction pathways for the combustion of methane.

\subsection{NO reaction path analysis}

\subsubsection{Fuel-lean conditions}

Figure 3 presents the reaction path diagram of the principal reactions involved in the NO chemistry at fuel-lean conditions, which has been obtained from the results of both the rate-of-production analysis and the sensitivity analysis. As shown in Fig. 3, the oxidation of $\mathrm{NH}_{3}$ leads to two main products: $\mathrm{NO}$ and $\mathrm{N}_{2}$. According to the data obtained from the simulations with the detailed kinetic mechanisms, around $23 \%$ of $\mathrm{NH}_{3}$ is converted to $\mathrm{NO}$ and $76 \%$ is converted to $\mathrm{N}_{2}$. The remaining amount, less than $1 \%$, comprises other $\mathrm{N}$-compounds such as $\mathrm{NO}_{2}$ and $\mathrm{N}_{2} \mathrm{O}$.

Concerning the reaction paths, $\mathrm{NH}_{3}$ is mainly converted to $\mathrm{NH}_{2}$ by hydrogen abstraction (Reaction $\mathrm{R} 6$ ). $\mathrm{NH}_{2}$ is then partly recycled back to $\mathrm{NH}_{3}$, essentially by reacting with the hydroperoxyl radical (Reaction R7).

$\mathrm{NH}_{3}+\mathrm{OH} \Leftrightarrow \mathrm{NH}_{2}+\mathrm{H}_{2} \mathrm{O}$

$\mathrm{NH}_{2}+\mathrm{HO}_{2} \Leftrightarrow \mathrm{NH}_{3}+\mathrm{O}_{2}$

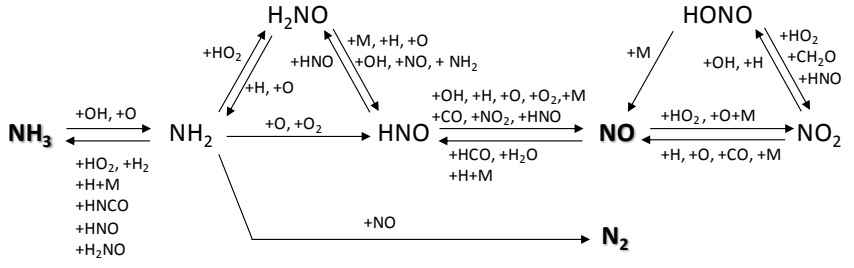

Figure 3. Reaction path diagram of the principal reactions involved in the NO chemistry at fuel-lean conditions.

The subsequent reactions of $\mathrm{NH}_{2}$ largely determine the formation of $\mathrm{N}_{2}$ or NO. Formation of $\mathrm{N}_{2}$ occurs mostly through the reaction of $\mathrm{NH}_{2}$ with $\mathrm{NO}$ (Reaction $\mathrm{R} 8$ ). This pathway accounts for $80 \%$ of the total $\mathrm{N}_{2}$ formation according to the results of the rate-of-production analysis.

$\mathrm{NH}_{2}+\mathrm{NO} \Leftrightarrow \mathrm{N}_{2}+\mathrm{H}_{2} \mathrm{O}$

NO formation occurs essentially by the oxidation of nitroxyl (Reaction R9, Fig. 4) through the sequence $\mathrm{NH}_{3} \rightarrow \mathrm{NH}_{2}$ $\left(\rightarrow \mathrm{H}_{2} \mathrm{NO}\right) \rightarrow \mathrm{HNO} \rightarrow \mathrm{NO}$ (Fig. 3). Thus nitroxyl can be formed directly by $\mathrm{NH}_{2}$ or via $\mathrm{H}_{2} \mathrm{NO}$ species. The reaction pathway involving $\mathrm{H}_{2} \mathrm{NO}$ has been identified as being important only in the presence of high $\mathrm{CO}_{2}$ concentrations (Mendiara and Glarborg, 2009).

$\mathrm{HNO}+\mathrm{O}_{2} \Leftrightarrow \mathrm{NO}+\mathrm{HO}_{2}$

Once $\mathrm{NO}$ is formed, some $\mathrm{NO}$ to $\mathrm{NO}_{2}$ interconversion occurs by the reaction of NO with the hydroperoxyl radical (Reaction R10).

$\mathrm{NO}+\mathrm{HO}_{2} \Leftrightarrow \mathrm{NO}_{2}+\mathrm{OH}$

(R10) 
Table 2. Normalized rate of production or normalized rate of consumption (negative values) of $\mathrm{NO}_{2}$ as a function of the temperature at fuel-lean conditions.

\begin{tabular}{lcccccccccccc}
\hline Reaction & \multicolumn{8}{c}{ Normalized rates of production or consumption of $\mathrm{NO}_{2}$} \\
\cline { 2 - 11 } & $773 \mathrm{~K}$ & $823 \mathrm{~K}$ & $873 \mathrm{~K}$ & $923 \mathrm{~K}$ & $973 \mathrm{~K}$ & $1023 \mathrm{~K}$ & $1073 \mathrm{~K}$ & $1123 \mathrm{~K}$ & $1173 \mathrm{~K}$ & $1223 \mathrm{~K}$ & $1273 \mathrm{~K}$ \\
\hline $\mathrm{NO}+\mathrm{HO}_{2} \leftrightarrow \mathrm{NO}_{2}+\mathrm{OH}$ & 1.00 & 1.00 & 1.00 & 0.99 & 0.97 & 0.85 & 0.93 & 0.96 & 0.96 & 0.93 & 0.89 \\
$\mathrm{NO}_{2}+\mathrm{HO}_{2} \leftrightarrow \mathrm{HONO}+\mathrm{O}_{2}$ & -0.45 & -0.40 & -0.28 & -0.19 & -0.18 & -0.27 & -0.07 & - & - & - & - & - \\
$\mathrm{NO}_{2}+\mathrm{CO} \leftrightarrow \mathrm{NO}+\mathrm{CO}$ & -0.52 & -0.55 & -0.64 & -0.67 & -0.60 & -0.33 & - & - & - & - & - \\
$\mathrm{NO}_{2}+\mathrm{H} \leftrightarrow \mathrm{NO}+\mathrm{OH}$ & - & - & - & -0.07 & -0.13 & -0.30 & -0.80 & -0.76 & -0.68 & -0.61 & -0.56 \\
$\mathrm{NO}_{2}+\mathrm{O} \leftrightarrow \mathrm{NO}+\mathrm{O}_{2}$ & - & - & - & - & - & - & -0.12 & -0.20 & -0.30 & -0.38 & -0.43 \\
\hline
\end{tabular}

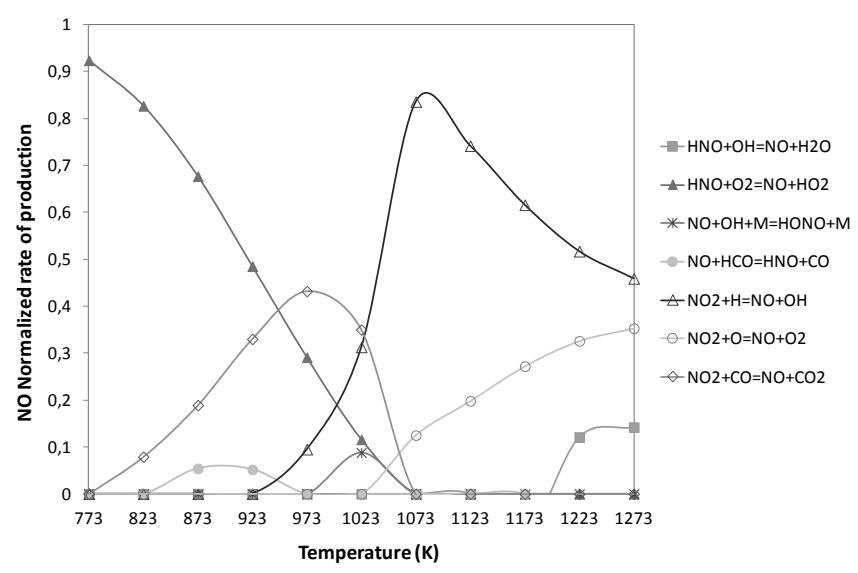

Figure 4. Normalized rate of production of NO at fuel-lean conditions $(\varphi=0.6)$.

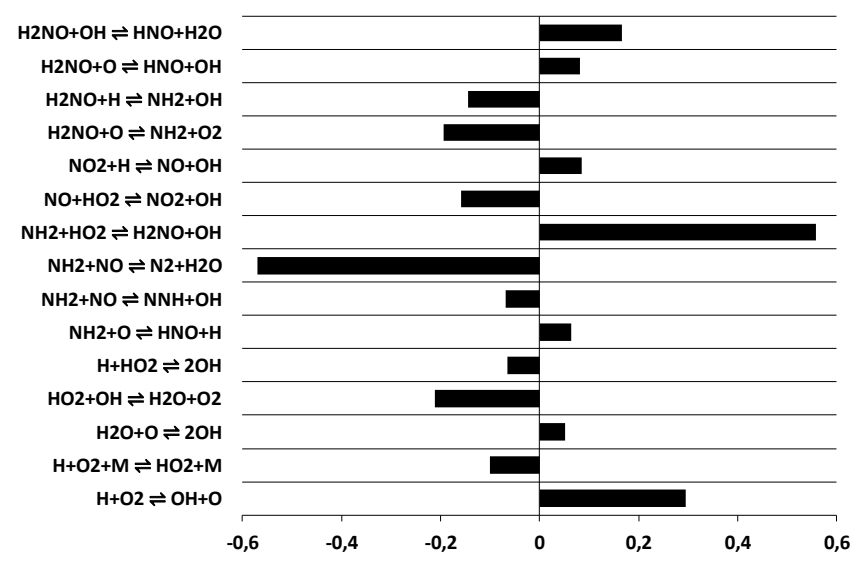

Figure 5. PSR code outputs for sensitivity analysis on NO at fuellean conditions $(\varphi=0.6)$ and $1073 \mathrm{~K}$.

However, part of the $\mathrm{NO}_{2}$ is converted back to $\mathrm{NO}$ directly or via HONO (Table 2). For temperatures lower than $1023 \mathrm{~K}$, $\mathrm{NO}_{2}$ reacts with $\mathrm{CO}$ to form $\mathrm{NO}$ and $\mathrm{CO}_{2}$ (Fig. 4, Reaction R11). It worth noting that in this range of temperatures the oxidation of $\mathrm{CO}$ is not efficient. For temperatures higher than $1023 \mathrm{~K}$, when the $\mathrm{NO}$ production is more efficient, $\mathrm{NO}_{2}$ is almost entirely converted back to NO by reacting with the

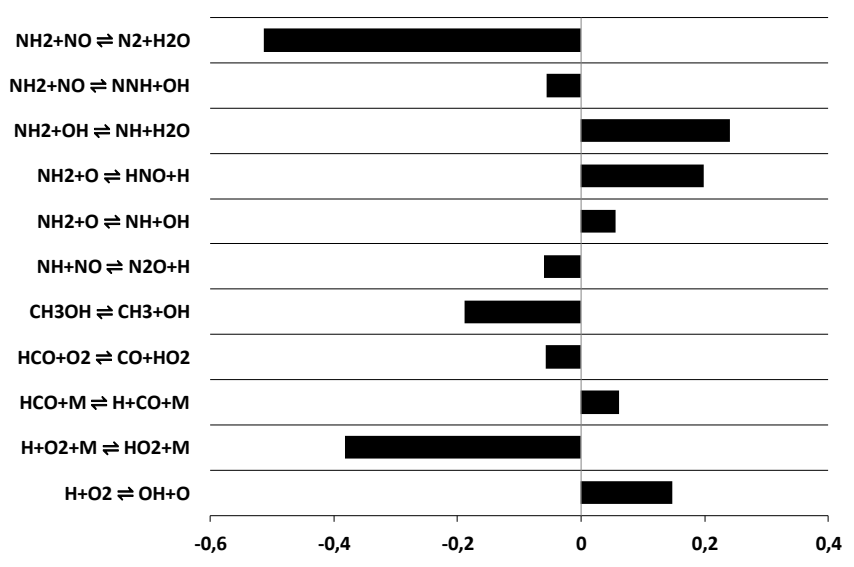

Figure 6. PSR code outputs for sensitivity analysis on NO at fuellean conditions $(\varphi=0.6)$ and $1273 \mathrm{~K}$.

$\mathrm{H}$ and $\mathrm{O}$ radicals (Reactions $\mathrm{R} 12$ and $\mathrm{R} 13$, Table 2). These two reactions are fast if their activation energy is considered (i.e. 362 and $600 \mathrm{cal} \mathrm{mol}^{-1}$, respectively). So in the presence of high concentrations of radicals, $\mathrm{NO}_{2}$ is rapidly converted back to NO (Miller and Bowman, 1989).

$$
\begin{aligned}
& \mathrm{NO}_{2}+\mathrm{CO} \Leftrightarrow \mathrm{NO}+\mathrm{CO}_{2} \\
& \mathrm{NO}_{2}+\mathrm{H} \Leftrightarrow \mathrm{NO}+\mathrm{OH} \\
& \mathrm{NO}_{2}+\mathrm{O} \Leftrightarrow \mathrm{NO}+\mathrm{O}_{2}
\end{aligned}
$$

$\mathrm{NO}$ is also removed to form $\mathrm{HNO}$ by reacting with $\mathrm{HCO}$ at high temperatures (Reaction R14). However, as $\mathrm{NO}_{2}$, $\mathrm{HNO}$ is almost entirely converted back to NO.

$$
\mathrm{NO}+\mathrm{HCO} \Leftrightarrow \mathrm{HNO}+\mathrm{CO}
$$

Figures 5 and 6 present the results of the sensitivity analysis at $1073 \mathrm{~K}$ and $1273 \mathrm{~K}$, respectively. This range of temperatures corresponds to the more efficient NO production in the conditions of this study. In these figures, a positive sensitivity coefficient of the reaction indicates that increasing the corresponding reaction rate in a forward direction contributes to increases in NO concentrations, and a negative sensitivity indicates the opposite. 


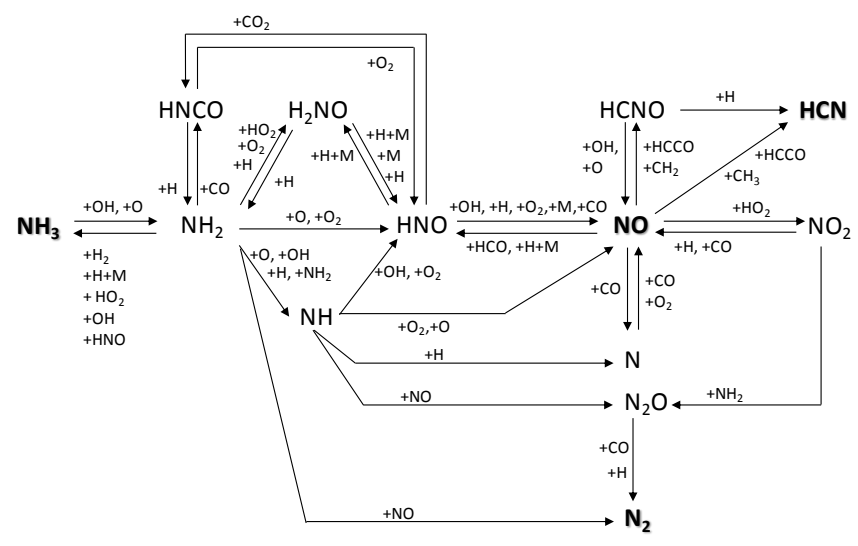

Figure 7. Reaction path diagram of the principal reactions involved in the NO chemistry at fuel-rich conditions.

The sensitivity analysis highlights how the NO chemistry strongly depends on reactions involving $\mathrm{NH}_{2}$, the influence of the $\mathrm{H}_{2} \mathrm{NO}$ route and the importance of the composition of the radical pool. As temperature increases, according to the results of the sensitivity analysis at $1273 \mathrm{~K}$, reactions involving hydrocarbon radicals and $\mathrm{CO}$ become relevant in the $\mathrm{NO}$ chemistry.

\subsubsection{Fuel-rich conditions}

At fuel-rich conditions NO chemistry is more complex than at fuel-lean conditions as indicated by the reaction path diagram presented in Fig. 7. In these conditions, $83 \%$ of $\mathrm{NH}_{3}$ leads to the formation of $\mathrm{N}_{2}$ and NO. The remaining amount of $\mathrm{NH}_{3}$ is principally converted to $\mathrm{HCN}$.

As at fuel-lean conditions, $\mathrm{NH}_{3}$ is mainly converted to $\mathrm{NH}_{2}$ by hydrogen abstraction (Reaction R6). Moreover, at fuel-rich conditions and temperatures higher than $1073 \mathrm{~K}$, reaction with oxygen atom (Reaction R15) also provides a non-negligible contribution to $\mathrm{NH}_{2}$ formation.

$\mathrm{NH}_{3}+\mathrm{O} \Leftrightarrow \mathrm{NH}_{2}+\mathrm{OH}$

Part of $\mathrm{NH}_{2}$ may be recycled to $\mathrm{NH}_{3}$ by reacting with the hydroperoxyl radical (Reaction R7), as at fuel-lean conditions. However, other reactions involving $\mathrm{NH}_{2}$ participate in the $\mathrm{NH}_{3}$ formation (Reactions $\mathrm{R} 16-\mathrm{R} 18$ ).

$\mathrm{NH}_{2}+\mathrm{H}_{2} \Leftrightarrow \mathrm{NH}_{3}+\mathrm{H}$

$\mathrm{NH}_{2}+\mathrm{H}+\mathrm{M} \Leftrightarrow \mathrm{NH}_{3}+\mathrm{M}$

$\mathrm{NH}_{2}+\mathrm{HNCO} \Leftrightarrow \mathrm{NH}_{3}+\mathrm{NCO}$

The subsequent reactions of $\mathrm{NH}_{2}$ largely determine the formation of $\mathrm{N}$-containing compounds since the formation of $\mathrm{N}_{2}, \mathrm{~N}_{2} \mathrm{O}$ and $\mathrm{NO}$ mostly occur by reactions involving amine radical species.
The formation of $\mathrm{N}_{2}$ follows essentially the same pathways as at fuel-lean conditions; this is through the reaction of $\mathrm{NH}_{2}$ with $\mathrm{NO}$ (Reaction R8). In the same way, $\mathrm{N}_{2} \mathrm{O}$ is also produced by the reaction of $\mathrm{NH}_{2}$ with $\mathrm{NO}$ (Reaction R19). This reaction represents a minor contribution in NO consumption in the conditions of this study. The normalized rate of consumption of $\mathrm{NO}$ due to this reaction at $1273 \mathrm{~K}$ is -0.055 . Moreover, $\mathrm{N}_{2} \mathrm{O}$ is almost entirely consumed to form $\mathrm{N}_{2}$ by reaction with $\mathrm{CO}$ and to a lower extent with $\mathrm{H}$.

$\mathrm{NH}_{2}+\mathrm{NO} \Leftrightarrow \mathrm{N}_{2} \mathrm{O}+\mathrm{H}$

Concerning NO, it is mostly produced by reactions involving HNO (Fig. 8). Between 773 and $1023 \mathrm{~K}$, the oxidation of HNO (Reaction R9) is the main source of NO, but also the reactions of $\mathrm{HNO}$ with $\mathrm{CO}$ (reverse Reaction R14) or the thermal dissociation of HNO (Reaction R20) contribute to the NO formation. For higher temperatures the reaction of $\mathrm{HNO}$ with the $\mathrm{H}$ radical (Reaction R21) becomes significant.

$\mathrm{HNO}+\mathrm{M} \Leftrightarrow \mathrm{NO}+\mathrm{H}+\mathrm{M}$

$\mathrm{HNO}+\mathrm{H} \Leftrightarrow \mathrm{NO}+\mathrm{H}_{2}$

$\mathrm{HNO}$ is mainly formed by $\mathrm{NH}_{2}$ and $\mathrm{H}_{2} \mathrm{NO}$, but also by the isocyanic acid ( $\mathrm{HNCO}$ ) due to the reaction $\mathrm{NH}_{2}+\mathrm{CO}$. The presence of $\mathrm{CO}$ in the degradation gases of vegetation enhances this reaction. However, this route of HNO formation is only important for temperatures from 873 to $1073 \mathrm{~K}$, where the $\mathrm{CO}$ oxidation is not efficient.

At high temperatures, from $1173 \mathrm{~K}$ and on, $\mathrm{NO}$ is also formed through other species than HNO. The most important reaction involves $\mathrm{CO}_{2}$ (Reaction R22), but $\mathrm{HCNO}$ and $\mathrm{NH}$ also contribute to the $\mathrm{NO}$ formation.

$\mathrm{CO}_{2}+\mathrm{N} \Leftrightarrow \mathrm{CO}+\mathrm{NO}$

As at fuel-lean conditions, once NO is formed, some NO to $\mathrm{NO}_{2}$ interconversion occurs by the reaction of $\mathrm{NO}$ with the hydroperoxyl radical (Reaction R10). However, $\mathrm{NO}_{2}$ is converted back to NO (Table 3 ) through reactions with CO (Reaction R11) and H radical (Reaction R12). For temperatures higher than $1123 \mathrm{~K}$, all the $\mathrm{NO}_{2}$ produced is recycled back to NO.

For temperatures higher than $1123 \mathrm{~K}$, different reaction paths participate on the NO consumption (Fig. 9). The contribution of the sequence NO $\rightarrow \mathrm{HNO}$ (Reactions R14 and $\mathrm{R} 20$ ) in NO removal is lower than $20 \%$. It is worth noting that both reactions contribute to the NO production up to $1073 \mathrm{~K}$, as previously detailed. So temperature changes the direction of the reaction. As at fuel-lean conditions, $\mathrm{HNO}$ is converted almost completely back to reform $\mathrm{NO}$ by reaction with the $\mathrm{H}$ atom.

Another important pathway on the NO removal at high temperatures is the route of NO reduction involving ketenyl 
Table 3. Normalized rate of production or normalized rate of consumption (negative values) of $\mathrm{NO}_{2}$ as a function of the temperature at fuel-rich conditions.

\begin{tabular}{|c|c|c|c|c|c|c|c|c|c|c|c|}
\hline \multirow[t]{2}{*}{ Reaction } & \multicolumn{11}{|c|}{ Normalized rates of production or consumption of $\mathrm{NO}_{2}$} \\
\hline & $773 \mathrm{~K}$ & $823 \mathrm{~K}$ & $873 \mathrm{~K}$ & $923 \mathrm{~K}$ & $973 \mathrm{~K}$ & $1023 \mathrm{~K}$ & $1073 \mathrm{~K}$ & $1123 \mathrm{~K}$ & $1173 \mathrm{~K}$ & $1223 \mathrm{~K}$ & $1273 \mathrm{~K}$ \\
\hline $\mathrm{NO}+\mathrm{HO}_{2} \leftrightarrow \mathrm{NO}_{2}+\mathrm{OH}$ & 1.00 & 1.00 & 1.00 & 1.00 & 1.00 & 1.00 & 1.00 & 0.99 & 0.99 & 0.99 & 0.99 \\
\hline $\mathrm{NO}_{2}+\mathrm{CO} \leftrightarrow \mathrm{NO}+\mathrm{CO}_{2}$ & -0.86 & -0.87 & -0.91 & -0.93 & -0.93 & -0.90 & -0.81 & - & - & - & - \\
\hline $\mathrm{NO}_{2}+\mathrm{H} \leftrightarrow \mathrm{NO}+\mathrm{OH}$ & - & - & - & - & - & - & -0.10 & -0.98 & -0.99 & -0.99 & -0.99 \\
\hline
\end{tabular}

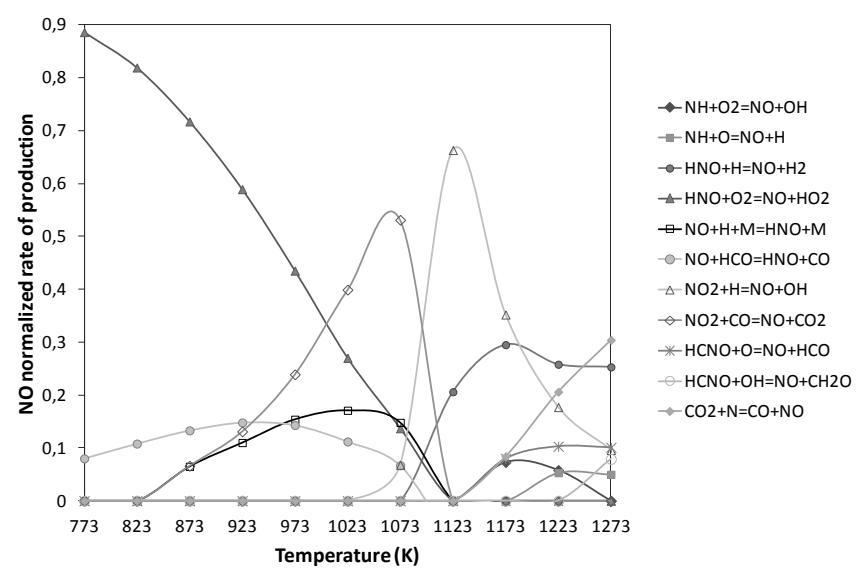

Figure 8. Normalized rate of production of $\mathrm{NO}$ at fuel-rich conditions $(\varphi=1.4)$.

radicals (Reactions R23 and R24), which results from the interaction of hydrocarbon and nitrogen species. The impact of these reactions on NO consumption increases with temperature. At $1273 \mathrm{~K}$ the normalized rate of consumption of NO to form $\mathrm{HCNO}$ is equal to -0.321 , whereas to form $\mathrm{HCN}$ it is equal to -0.144 .

$$
\begin{aligned}
& \mathrm{HCCO}+\mathrm{NO} \Leftrightarrow \mathrm{HCNO}+\mathrm{CO} \\
& \mathrm{HCCO}+\mathrm{NO} \Leftrightarrow \mathrm{HCN}+\mathrm{CO}_{2}
\end{aligned}
$$

The importance of the branching ratio for the $\mathrm{HCCO} / \mathrm{NO}$ reactions depends on the fate of $\mathrm{HCNO}$ (Glarborg et al., 1998). HCNO mostly reforms NO by reacting with oxygenated radicals (Reactions R25 and R26), and produces $\mathrm{HCN}$ by reaction with hydrogen atoms (Reaction R27).

$$
\begin{aligned}
& \mathrm{HCNO}+\mathrm{O} \Leftrightarrow \mathrm{NO}+\mathrm{HCO} \\
& \mathrm{HCNO}+\mathrm{OH} \Leftrightarrow \mathrm{NO}+\mathrm{CH}_{2} \mathrm{O} \\
& \mathrm{HCNO}+\mathrm{H} \Leftrightarrow \mathrm{HCN}+\mathrm{OH}
\end{aligned}
$$

In the conditions of this study, the route $\mathrm{HCNO} \rightarrow \mathrm{NO}$ prevails over the route $\mathrm{HCNO} \rightarrow \mathrm{HCN}$. At $1273 \mathrm{~K}$ where the reactions $\mathrm{HCCO}+\mathrm{NO}$ (Reactions R23 and R24) are more significant, the normalized rate of consumption of HCNO to

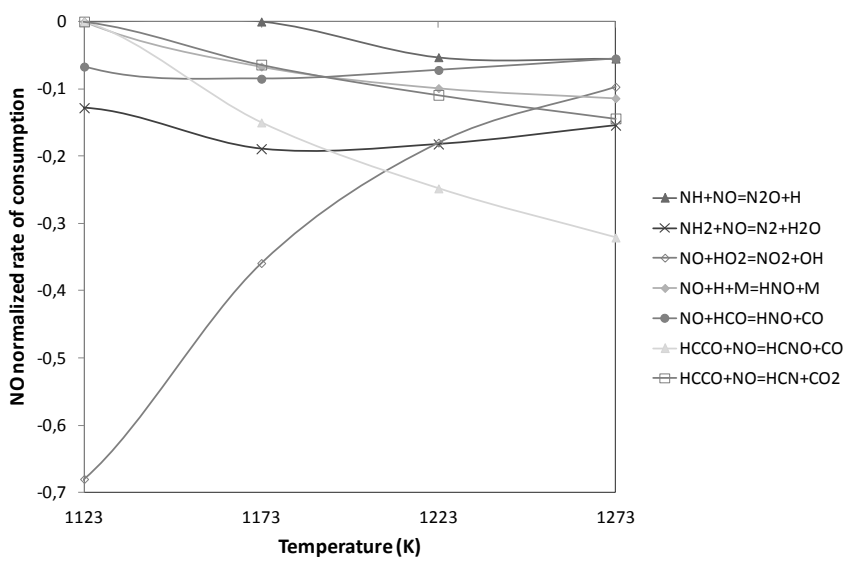

Figure 9. Normalized rate of consumption of NO at fuel-rich conditions $(\varphi=1.4)$.

form NO (Reactions R25 and R26) is equal to 0.569, while to form HCN (Reaction R27) it is equal to 0.425 . For lower temperatures the difference between both values is higher.

It is worth noting that even the well-known reaction of formation of $\mathrm{HCN}$ by means of the reaction of $\mathrm{CH}_{3}$ and $\mathrm{NO}$ (Reaction R28) participates in the $\mathrm{HCN}$ production; its contribution to the NO consumption represents less than $5 \%$ of the total NO consumption according to the rate-of-production analysis. Moreover, this reaction is only important at temperatures lower than $1123 \mathrm{~K}$, where neither the production of $\mathrm{HCN}$ nor the production of $\mathrm{NO}$ is efficient.

$$
\mathrm{CH}_{3}+\mathrm{NO} \Leftrightarrow \mathrm{HCN}+\mathrm{H}_{2} \mathrm{O}
$$

The sensitivity analysis results at $1073 \mathrm{~K}$ (Fig. 10) and $1273 \mathrm{~K}$ (Fig. 11) illustrate the complex chemistry of NO at fuel-rich conditions. Results of the sensitivity analysis emphasize the importance of the fate of the hydrocarbon radicals on the NO chemistry. The branching reactions leading either to $\mathrm{C}_{2} \mathrm{H}_{6}$ or $\mathrm{CH}_{2} \mathrm{O}\left(\mathrm{CH}_{3} \mathrm{O}\right)$ enhance the removal or the production of $\mathrm{NO}$, respectively, by the subsequent formation of radicals such as $\mathrm{HCCO}$ in the case of $\mathrm{C}_{2} \mathrm{H}_{6}$ (see Fig. 2). 


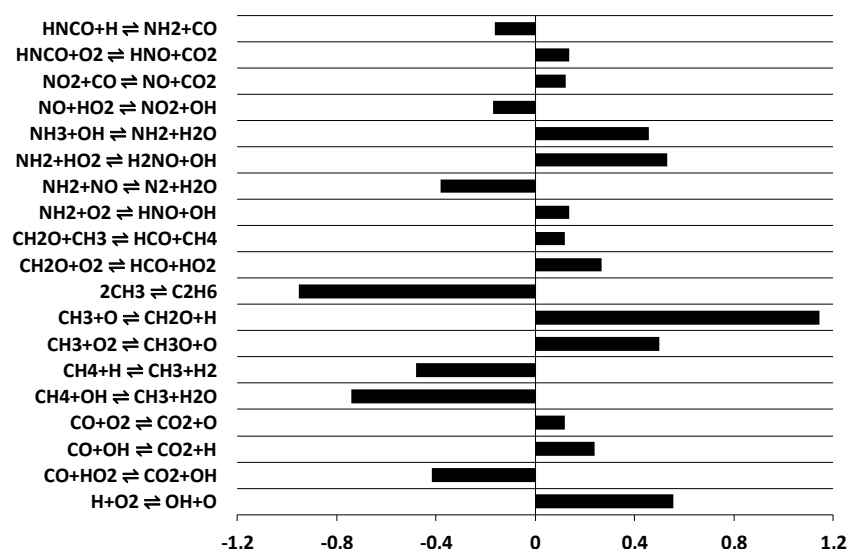

Figure 10. PSR code outputs for sensitivity analysis on NO at fuelrich conditions $(\varphi=1.4)$ and $1073 \mathrm{~K}$.

\section{NO modelling}

\subsection{Derivation of the NO global kinetic model}

The growing concern for the environment and the increasingly stringent emissions standards in both Europe and the United States have promoted the development of global kinetic mechanisms to study the NO formation in combustion processes, particularly those associated with industrial applications. Thus, the oxidation of $\mathrm{NH}_{3}$ has been modelled in the simplest way by a two-step scheme (Reactions R29 and R30) as proposed by several authors (De Soete, 1975; Mitchell and Tarbell, 1982).

$$
\begin{aligned}
& N 1: \mathrm{NH}_{3}+\mathrm{O}_{2} \Rightarrow \mathrm{NO}+\mathrm{H}_{2} \mathrm{O}+\frac{1}{2} \mathrm{H}_{2} \\
& N 2: \mathrm{NH}_{3}+\mathrm{NO} \Rightarrow \mathrm{N}_{2}+\mathrm{H}_{2} \mathrm{O}+\frac{1}{2} \mathrm{H}_{2}
\end{aligned}
$$

This two-step mechanism represents fairly well the NO chemistry at fuel-lean conditions in relation with the reaction path analysis and the sensitivity analysis. At fuel-rich conditions the sensitization of hydrocarbon radicals and $\mathrm{CO} / \mathrm{CO}_{2}$ to NO is more significant. Moreover, the consumption of $\mathrm{NO}$ to form HCN through the sequence $\mathrm{HCCO}(\rightarrow \mathrm{HCNO}) \rightarrow$ $\mathrm{HCN}$ acquires more importance as temperature increases.

The number of chemical species and global steps included in the kinetic mechanism must be a balance of the competing needs of accuracy and simplicity to attain the computation time requirements. Moreover, the kinetic model has to be suitable for all different conditions encountered in a wildfire (i.e. both fuel-lean and fuel-rich conditions, different degradation gas composition and temperatures, etc.).

So to keep the kinetic mechanism simple, we decided to model the NO chemistry from fuel-bound nitrogen by the reaction scheme presented in Reactions (R29) and (R30) and therefore to omit the consumption of NO to form HCN. It is worth noting that this mechanism is only important at fuel-

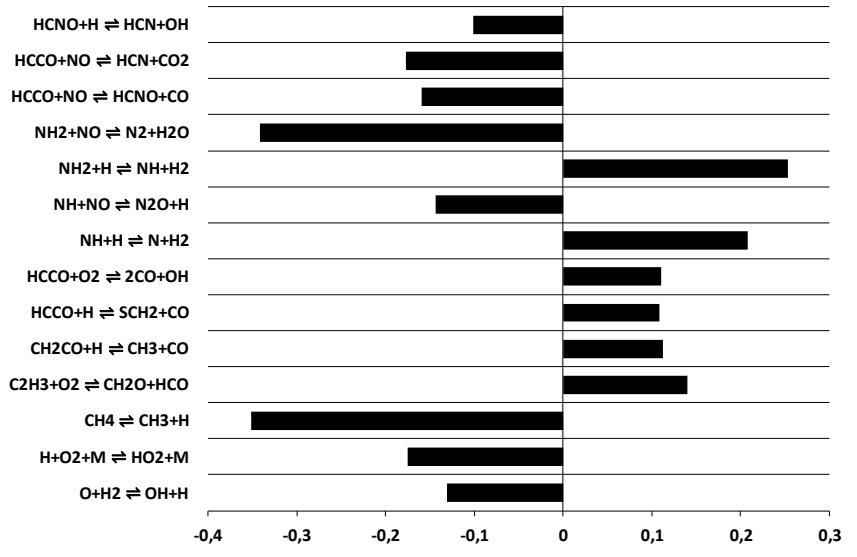

Figure 11. PSR code outputs for sensitivity analysis on NO at fuelrich conditions $(\varphi=1.4)$ and $1273 \mathrm{~K}$.

rich conditions and temperatures higher than $1173 \mathrm{~K}$. Moreover, the contribution of this reaction pathway to the consumption of NO varies between $10 \%$ at 1173 and $28 \%$ at $1273 \mathrm{~K}$, as already detailed in the previous section.

To determine the rate of $\mathrm{NH}_{3}$ oxidation reaction (Reaction R29), the classical steady-state assumption was used to relate the $\mathrm{OH}$ radical to the main components, since the most important reaction on the consumption of ammonia in the conditions of this study is that with the $\mathrm{OH}$ radical (Reaction R6). Consequently the $\mathrm{OH}$ radical was supposed to be proportional to the square root of the product of $\mathrm{O}_{2}$ and $\mathrm{H}_{2}$ concentrations.

Concerning the reaction of NO consumption (Reaction R30), it was assumed that its reaction rate was first order in $\mathrm{NH}_{3}$ and $\mathrm{NO}$. In addition, due to the different reaction pathways of NO consumption depending on the fuel equivalence ratio, as indicated by the results of the reaction path analysis and previously mentioned, a function of the equivalence ratio was added to the formal expression corresponding to the reaction rate of $\mathrm{NO}$ consumption.

Both global mechanisms were coupled without taking into account the possible effects of sensitization of $\mathrm{CH}_{4}$ and $\mathrm{CO} / \mathrm{CO}_{2}$ to $\mathrm{NO}$.

\subsection{Model fitting}

The reaction rate expressions of the global model obtained from the calibration are given by Eqs. (1) and (2), where $\dot{\omega}$ is expressed in $\mathrm{mol} \times \mathrm{cm}^{-3} \times \mathrm{s}^{-1}$.

$$
\begin{gathered}
\dot{\omega}_{\{N 1\}}=k_{\{N 1\}} T^{2}\left[\mathrm{NH}_{3}\right]^{1.00}\left[\mathrm{H}_{2}\right]^{0.50}\left[\mathrm{O}_{2}\right]^{0.50} \exp \left[-\frac{62000}{R T}\right] \\
\dot{\omega}_{\{N 2\}}=k_{\{N 2\}} T^{-1.3}\left[\mathrm{NH}_{3}\right]^{1.00}[\mathrm{NO}]^{1.00} \exp \left[-\frac{37000}{R T}\right]
\end{gathered}
$$



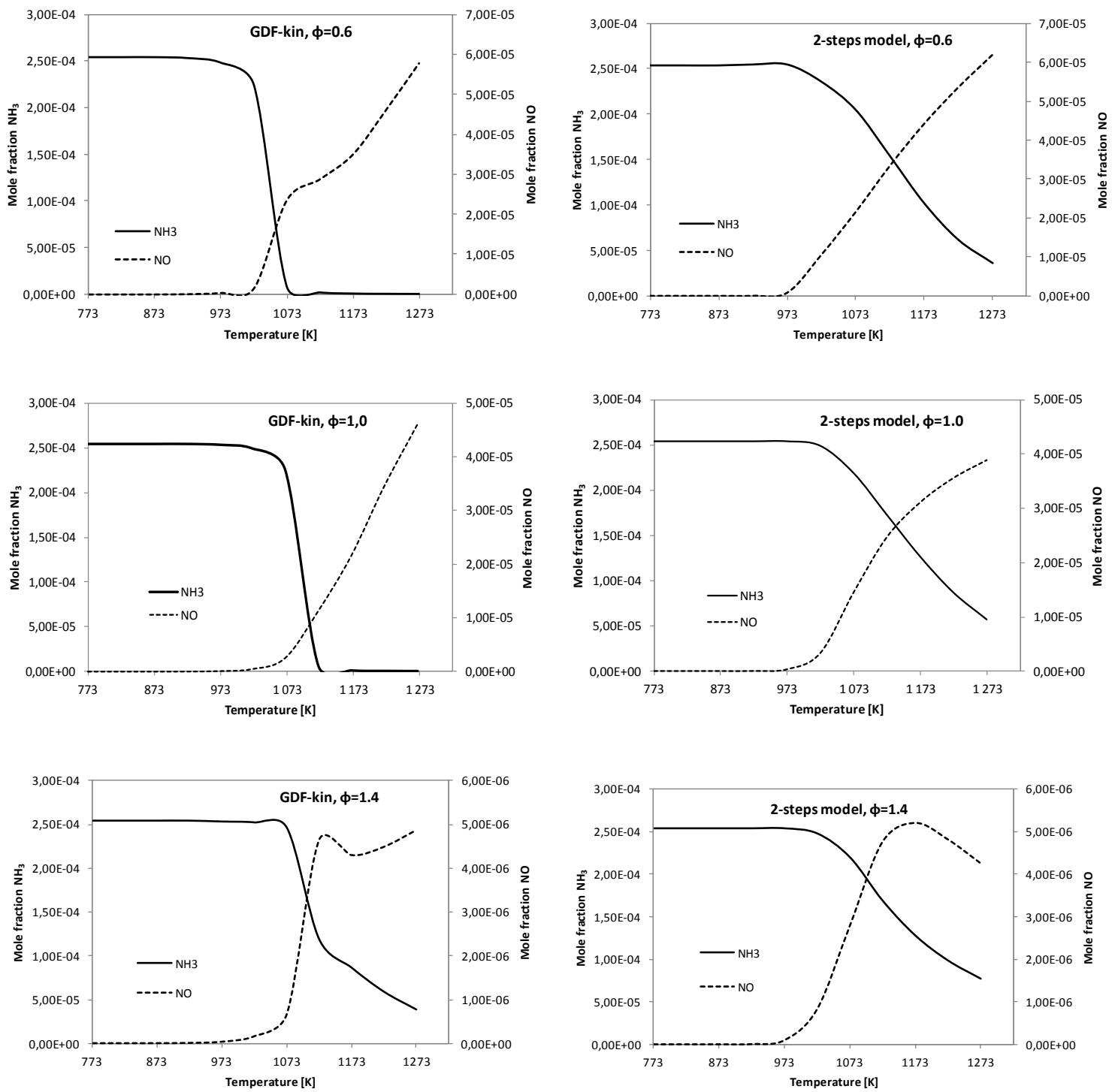

Figure 12. Comparison between the $\mathrm{NO}$ and $\mathrm{NH}_{3}$ mole fractions concentrations obtained with the detailed mechanism GDF-Kin ${ }^{\circledR} 3.0$ and the global model developed in the present work as a function of the temperature, and for different equivalence ratios (i.e. $\varphi=0.6$, 1.0 and 1.4), for a residence time of $1.3 \mathrm{~s}$

where $k_{\{N 1\}}$ is equal to $3.2210^{12}$ and $k_{\{N 2\}}$ is given by Eq. (3).

$k_{\{N 2\}}=\exp \left(45.7+\Gamma(\phi-1) \cdot \phi^{2}\right)$

where $\varphi$ is the fuel equivalence ratio and $\Gamma(x)$ is the unit step function (Eq. 4).

$\Gamma(x)= \begin{cases}0 & x \leq 0 \\ 1 & x>0\end{cases}$

Figure 12 shows the comparison between the calculated $\mathrm{NH}_{3}$ and NO concentrations (mole fraction), as a function of the temperature using the global reaction mechanism, and the reference detailed chemistry, for the different fuel equivalence ratios (i.e. 0.6, 1.0 and 1.4).

As it can be seen in this figure, the NO concentration profiles are properly predicted with the global model both at fuel-lean and fuel-rich conditions. The differences between the overall production of $\mathrm{NO}$ at $1273 \mathrm{~K}$ obtained with the global and the detailed mechanism are 7.4, 11.7 and $12.6 \%$, respectively, for an equivalence ratio of $0.6,1.0$ and 1.4.

Regarding $\mathrm{NH}_{3}$, there is also a good agreement in general terms between the predicted concentration profiles by the global model and the detailed mechanism. However, the oxidation of $\mathrm{NH}_{3}$ as a function of the temperature is sharper when predicted by the detailed mechanism GDF-Kin ${ }^{\circledR} 3.0$ than when predicted by the global model, especially at fuel- 
Table 4. Percentage of $\mathrm{NH}_{3}$ conversion to NO.

\begin{tabular}{lll}
\hline$\varphi$ & GDF-Kin ${ }^{\circledR} 3.0$ & $\begin{array}{l}\text { Two-step global } \\
\text { model }\end{array}$ \\
\hline 0.6 & 22.8 & 28.5 \\
1.0 & 18.1 & 19.8 \\
1.4 & 2.3 & 2.4 \\
\hline
\end{tabular}

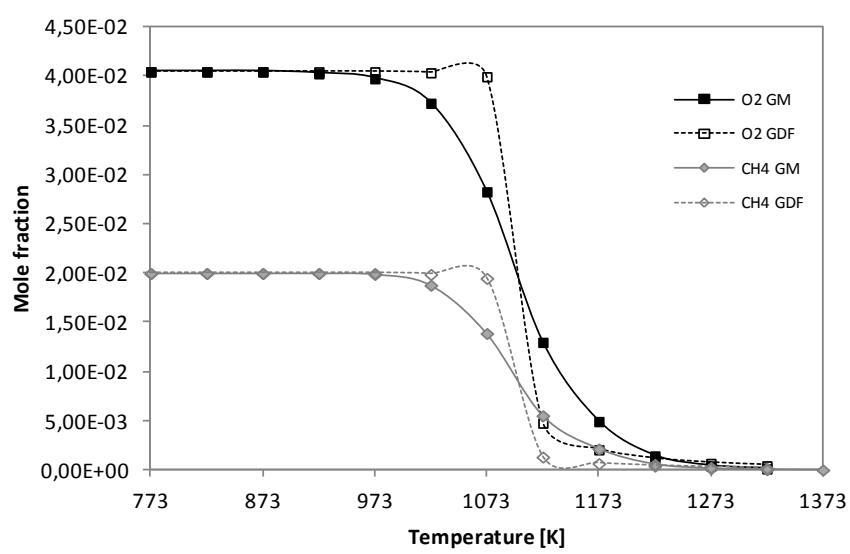

Figure 13. Comparison between the $\mathrm{CH}_{4}$ and $\mathrm{O}_{2}$ mole fractions concentrations obtained with the detailed mechanism GDF-Kin ${ }^{\circledR}$ 3.0 (GDF on the legend) and the global model (GM on the legend) as a function of the temperature at fuel-rich conditions.

lean and stoichiometric conditions. As a result, the global model is not able to predict the entire consumption of $\mathrm{NH}_{3}$. The relative errors in the prediction of the global consumption of $\mathrm{NH}_{3}$ by the global model in comparison with the detailed mechanisms are $14.1,9.5$ and $17.8 \%$, respectively, for an equivalence ratio of $0.6,1.0$ and 1.4.

If the percentage of $\mathrm{NH}_{3}$ converted into $\mathrm{NO}$ is computed, the values obtained with GDF-Kin ${ }^{\circledR} 3.0$ and the global model are fairly similar (Table 4). The largest divergence is observed at fuel-lean conditions, where the global model overpredicts the conversion of $\mathrm{NH}_{3}$ to $\mathrm{NO}$ because of the error induced by the $\mathrm{NH}_{3}$ predictions.

Concerning the other major chemical species present in the gas mixture of the degradation gases of vegetation, Figs. 13 and 14 show, respectively, the $\mathrm{CH}_{4}$ and $\mathrm{O}_{2}$; and $\mathrm{CO}$ and $\mathrm{CO}_{2}$ concentration profiles as a function of the temperature at a fuel equivalence ratio of 1.4. In these conditions, there is a good agreement between the results obtained with both kinetic mechanisms. At stoichiometric and fuel-lean conditions, results show that the predicted temperature at which $\mathrm{CH}_{4}, \mathrm{CO}, \mathrm{CO}_{2}$ and $\mathrm{O}_{2}$ start being consumed or produced is higher when using the detailed mechanism, as it can be seen in Fig. 15 for the particular case of $\mathrm{CH}_{4}$ at fuel-lean conditions. The reaction temperature has shifted $50 \mathrm{~K}$ due to the sensitization of these species to NO. The discrepancy between the predictions of the global model and the detailed

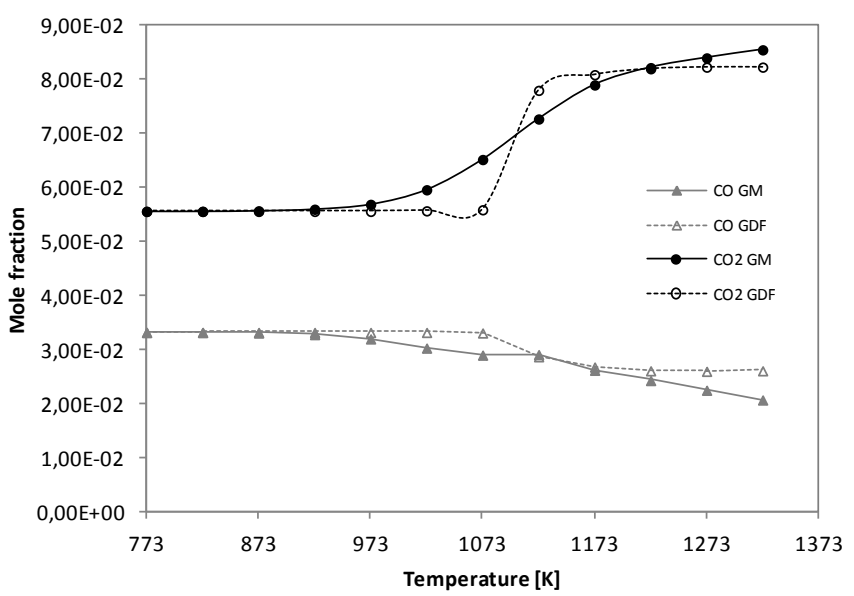

Figure 14. Comparison between the $\mathrm{CO}$ and $\mathrm{CO}_{2}$ mole fractions concentrations obtained with the detailed mechanism GDF-Kin ${ }^{\circledR}$ 3.0 (GDF on the legend) and the global model (GM on the legend) as a function of the temperature at fuel-rich conditions.

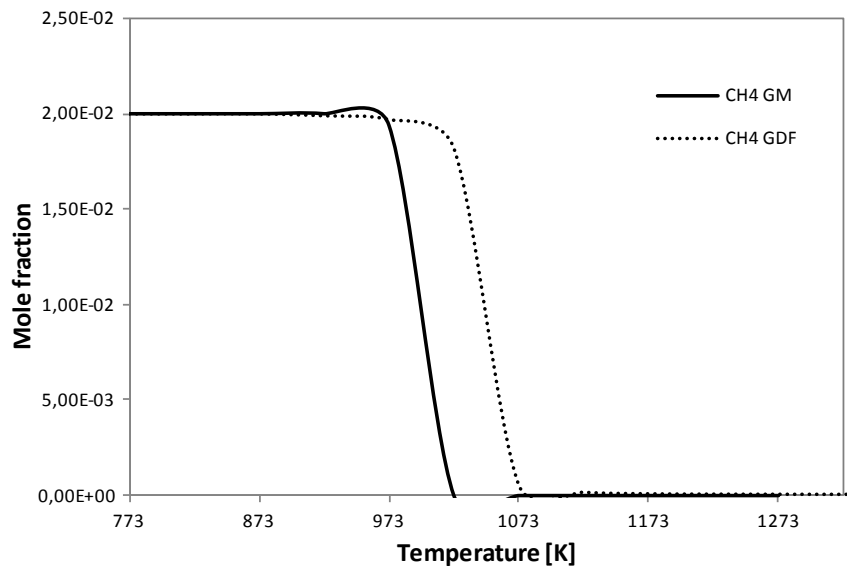

Figure 15. Comparison between the $\mathrm{CH}_{4}$ mole fractions concentrations obtained with the detailed mechanism GDF-Kin ${ }^{\circledR} 3.0$ (GDF on the legend) and the global model (GM on the legend) as a function of the temperature at fuel-lean conditions.

mechanism is only in terms of the temperature of oxidation/production of $\mathrm{CH}_{4}, \mathrm{CO}, \mathrm{CO}_{2}$ and $\mathrm{O}_{2}$; since this difference is only about $50 \mathrm{~K}$, predictions of the global model can reasonably be considered as fairly accurate predictions.

\section{Discussion}

\subsection{Model testing}

In order to test the model in conditions other than the fitting conditions, the model was tested for another residence time (i.e. $0.6 \mathrm{~s}$ ) representative of the conditions encountered during a wildfire. 

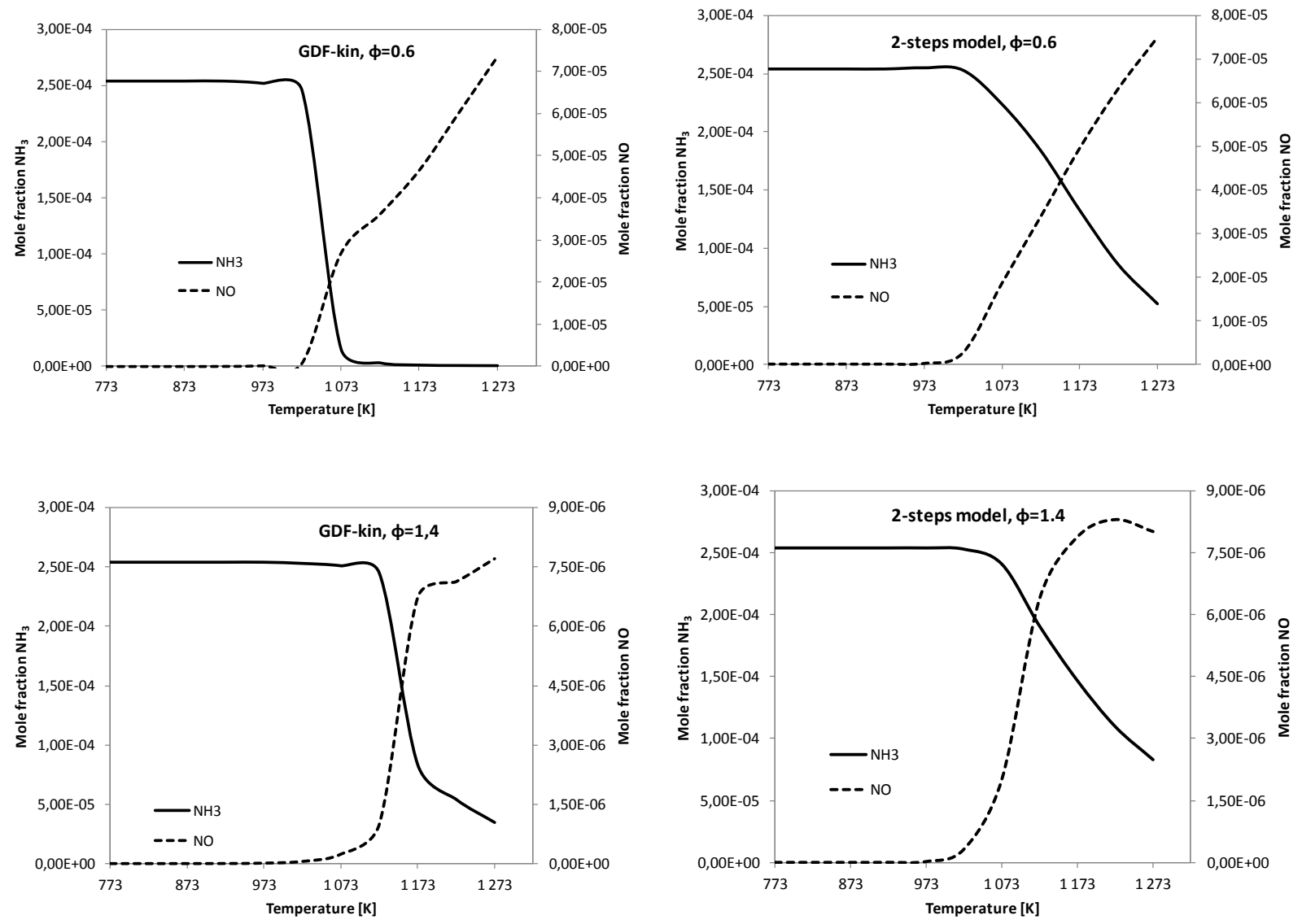

Figure 16. Comparison between the $\mathrm{NO}$ and $\mathrm{NH}_{3}$ mole fractions concentrations obtained with the detailed mechanism GDF-Kin ${ }^{\circledR} 3.0$ and the global model developed in the present work as a function of the temperature, and for different equivalence ratios (i.e. $\varphi=0.6$ and 1.4 ), for a residence time of $0.6 \mathrm{~s}$.

Figure 16 presents the results of the calculated $\mathrm{NH}_{3}$ and NO concentrations (mole fraction) as a function of the temperature by using the global model and the reference detailed mechanism at fuel-lean and fuel-rich conditions, corresponding to fuel equivalence ratios of 0.6 and 1.4, respectively. As it can be seen in this figure, the NO concentration profiles are accurately predicted with the global model. The differences between the overall production of $\mathrm{NO}$ at $1273 \mathrm{~K}$ obtained with the global and the detailed mechanisms are 2.0 and $4.3 \%$, respectively, for an equivalence ratio of 0.6 and 1.4 .

Concerning $\mathrm{NH}_{3}$, as for a residence time of $1.3 \mathrm{~s}$, even though there is also a general good agreement between the predicted concentration profiles by the global model and the detailed mechanism, the concentration of $\mathrm{NH}_{3}$ as a function of the temperature drops sharply when predicted by the detailed mechanism compared to when predicted by the global model. Thus, the global model is not able to predict the entire consumption of $\mathrm{NH}_{3}$. In this case, the relative errors in the predictions of the global $\mathrm{NH}_{3}$ consumption by the global model in comparison with the detailed mechanisms are, respectively, for an equivalence ratio of 0.6 and 1.4, 20.6 and $22.0 \%$.
Conversion factors of $\mathrm{NH}_{3}$ to $\mathrm{NO}$ computed by the values obtained with the global model are 37.3 and $4.7 \%$ for fuellean and fuel-rich conditions, respectively. The corresponding values obtained with the detailed kinetic mechanism are 29 and $3.5 \%$. As for a residence time of $1.3 \mathrm{~s}$, the observed differences between prediction with the global model and the detailed kinetic mechanism are due to the error in the prediction of the entire consumption of $\mathrm{NH}_{3}$ by the global model.

For the other major chemical species present in the gas mixture of the degradation gases of vegetation, $\mathrm{CH}_{4}, \mathrm{O}_{2}, \mathrm{CO}$ and $\mathrm{CO}_{2}$, the concentration profiles as a function of the temperature are properly predicted at both fuel-lean and fuel-rich conditions. In this case no shift of the reaction temperature is produced as it was observed for a residence time of $1.3 \mathrm{~s}$. Thus, the NO global model coupled to the $\mathrm{CH}_{4} / \mathrm{CO}$ model captures the essential features of the NO chemistry.

\subsection{Comparison to experimental data available in the literature}

To our knowledge, there are no experimental data in the literature concerning the NO formation in PSR devices for 
$\mathrm{CH}_{4} / \mathrm{CO} / \mathrm{CO}_{2} / \mathrm{NH}_{3}$ gas mixtures in the conditions of this study. An experimental study performed in a PSR device that presents conditions close to the present work is that of Dagaut et al. (1998). The experimental data of this work were used to develop the model for the NO chemistry included in the detailed mechanism of reference. Therefore, comparing our results with these data will not actually provide new information.

Thus, in order to back up at least in the order of magnitude the present results with experimental data, we have compared the results of this work in terms of $\mathrm{NH}_{3}$ conversion to $\mathrm{NO}$ with the work of Mendiara and Glarborg (2009).

Mendiara and Glarborg (2009) studied the ammonia chemistry in the oxy-fuel combustion of methane. Experiments were performed in a flow reactor at temperatures ranging between $973 \mathrm{~K}$ and $1773 \mathrm{~K}$, at different fuel equivalence ratios and for $\mathrm{CH}_{4} / \mathrm{NH}_{3}$ mixtures highly diluted in $\mathrm{CO}_{2}$ or $\mathrm{N}_{2}$. The residence time in the reactor was of the order of $1 \mathrm{~s}$.

According to their results, conversion factors of $\mathrm{NH}_{3}$ to NO strongly depend on the presence of $\mathrm{CO}_{2}$ in the mixture. For $\mathrm{CH}_{4} / \mathrm{NH}_{3}$ mixtures diluted in $\mathrm{CO}_{2}$, the conversion of $\mathrm{NH}_{3}$ to form $\mathrm{NO}$ varied between $27 \%$ at fuel-lean conditions and $15 \%$ at fuel-rich conditions. For $\mathrm{CH}_{4} / \mathrm{NH}_{3}$ mixtures diluted in $\mathrm{N}_{2}$, these values were 47 and $4 \%$, respectively. Thus, as stated by Mendiara and Glarborg (2009), $\mathrm{CO}_{2}$ enhances the formation of $\mathrm{NO}$ under fuel-rich conditions while it inhibits the NO formation under stoichiometric and fuel-lean conditions.

The corresponding values predicted by the global model varied between $28.5 \%$ at fuel-lean conditions and $2.4 \%$ at fuel-rich conditions for a residence time of $1.3 \mathrm{~s}$, and between 37.3 and $4.7 \%$ for a residence time of $0.6 \mathrm{~s}$.

The results obtained with the two-step global mechanisms are consistent with the experimental data, especially concerning the simulations run for a residence time of $1.3 \mathrm{~s}$, which is a value closer to the conditions in which experimental data were obtained. However, a major difference is observed at fuel-rich conditions, since a greater amount of NO formation would be expected according to the experimental data of Mendiara and Glarborg (2009). Clearly, the high content of $\mathrm{CO}$ present in the gaseous mixture of degradation gases, but not in the mixture studied by Mendiara and Glarborg (2009), and the derived sensitization effects to $\mathrm{CH}_{4}$ and $\mathrm{NO}$ are responsible for this divergence. According to Glarborg and Bentzen (2008), high concentrations of CO in the oxidation of $\mathrm{CH}_{4}$ led to alterations in the amount and partitioning of $\mathrm{O} / \mathrm{H}$ radicals with implications on the $\mathrm{NH}_{3}$ conversion.

\section{Conclusions}

NO emissions from the combustion of vegetation at the source level have been studied numerically, considering that the volatile fraction of fuel- $\mathrm{N}$ released due to the thermal degradation of vegetation is composed by $\mathrm{NH}_{3}$. The main chemical pathways of NO formation and their occurrence depending on the conditions of this study have been established. NO is mainly produced through the sequence $\mathrm{NH}_{3} \rightarrow \mathrm{NH}_{2}\left(\rightarrow \mathrm{H}_{2} \mathrm{NO}\right) \rightarrow \mathrm{HNO} \rightarrow \mathrm{NO}\left(\leftrightarrow \mathrm{NO}_{2}\right)$. However, at fuel-rich conditions NO chemistry is more complex, and a larger number of chemical species and thus reaction pathways are involved in the processes of NO formation and consumption. Moreover, in these conditions the effects of sensitization of hydrocarbons and $\mathrm{CO} / \mathrm{CO}_{2}$ on $\mathrm{NO}$ are more significant. Thus, the conversion of $\mathrm{NH} 3$ (fuel-N) to NO strongly depends on the compounds present in the gaseous mixture, this is on the composition of the degradation gases. The conversion of $\mathrm{NH}_{3}$ to $\mathrm{NO}$ depends on the fuel-equivalence ratio as well.

According to the reaction path analysis through rate-ofproduction and the sensitivity analyses, a two-step global kinetic model has been proposed for the oxidation of ammonia. The obtained mechanism succeeds in predicting the final concentrations of $\mathrm{NO}$ and $\mathrm{NH}_{3}$ with reasonable accuracy in comparison with the numerical values obtained with the detailed kinetic mechanism GDF-Kin ${ }^{\circledR} 3.0$ for different conditions in terms of temperatures, fuel equivalence ratio and residence time.

Different gaseous mixtures containing $\mathrm{CH}_{4}, \mathrm{CO}, \mathrm{CO}_{2}$ and $\mathrm{NH}_{3}$ could be studied with the coupling of the two-step mechanism developed herein and the five-step mechanism for $\mathrm{CH}_{4} / \mathrm{CO}$.

The results of this work highlight the importance of improving the present knowledge on the combustion processes of vegetation in order to improve the modelling of wildfire emissions. Caution has to be observed with the simplifications of the composition of the degradation gases of vegetation because minor compounds, such as fuel-N, can have relevant implications on the chemistry of the pollutants emitted by wildfires.

Acknowledgements. This research was supported by the French National Research Agency (ANR), under the project ANR-09COSI-006 and by the French National Center for Scientific Research (CNRS).

Edited by: R. Lasaponara

Reviewed by: I. Gitas and one anonymous referee

\section{References}

Barboni, T., Cannac, M., Pasqualini, V., Simeoni, A., Leoni, E., and Chiaramonti, N.: Volatile and semi-volatile organic compounds in smoke exposure of firefighters during prescribed burning in the Mediterranean region. Int. J. Wildland Fire, 19, 606-612, 2010.

Bartok, W., Engleman, V. S., Goldstein, R., and del Valle, E. G.: Basic Kinetic Studies and Modeling of Nitrogen Oxide Formation in Combustion Processes. AICHE Sym. S., 126, 30-38, 1972. 
Brink, A., Boström, S., Kilpinen, P., and Hupa, M.: Modeling nitrogen chemistry in the freeboard of biomass-FBC, IFRF Combustion Journal, Article No 200107, 1-14, 2001.

Dagaut, P., Lecomte, F., Chevailler, S., and Cathonnet, M.: Experimental and detailed kinetic modeling of nitric oxide reduction by a natural gas blend in simulated reburning conditions. Combust. Sci. Technol., 139, 329-363, 1998.

David, R. and Matras, D.: Règles de construction et d'extrapolation des réacteurs auto-agités par jets gazeux. Can. J. Chem. Eng., 53, 297-300, 1975.

De Soete, G. G.: Overall Reaction Rates of $\mathrm{NO}$ and $\mathrm{N}_{2}$ Formation from Fuel Nitrogen, P. Combust. Inst., 15, 1093-1102, 1975.

Duterque, J., Avezard, N., and Borghi, R.: Further Results on Nitrogen Oxides Production in Combustion, Zones. Combust. Sci. Technol., 25, 85-89, 1981.

El Bakali, A., Dagaut, P., Pillier, L., Desgroux, P., Pauwels, J. F., Rida, A., and Meunier, P.: Experimental and modeling study of the oxidation of natural gas in a premixed flame, shock tube and jet-stirred reactor, Combust. Flame, 137, 109-128, 2004.

El Bakali, A., Pillier, L., Desgroux, P., Lefort, B., Gasnot, L., Pauwels, J. F., and da Costa, L.: NO prediction in natural gas flames using GDF-Kin ${ }^{\circledR} 3.0$ mechanism NCN and $\mathrm{HCN}$ contribution to prompt-NO formation, Fuel 85, 896-909, 2006.

Faravelli, T., Frassoldati, A., and Ranzi, E.: Kinetic modeling of the interactions between $\mathrm{NO}$ and hydrocarbons in the oxidation of hydrocarbons at low temperatures, Combust. Flame, 132, 188207, 2003.

Glarborg, P.: Hidden interactions - Trace species governing combustion and emissions, P. Combust. Inst., 31, 77-98, 2007.

Glarborg, P. and Bentzen, L. L. B.: Chemical effects of high $\mathrm{CO}_{2}$ concentration in oxy-fuel combustion of methane, Energ. Fuel., 22, 291-296, 2008.

Glarborg, P., Kee, R. J., Grcar, J. F., and Miller, J. A.: PSR: A FORTRAN Program for Modeling Well-Stirred Reactors. Report No.SAND 86-8209, Sandia National Laboratories, Albuquerque, NM, 1986.

Glarborg, P., Alzueta, M. U., Dam-Johansen, K., and Miller, A.: Kinetic modeling of hydrocarbon/nitric oxide interactions in a flow reactor, Combust. Flame, 115, 1-27, 1998.

Grewe, V., Dahlmann, K., Matthes, S., and Steinbrecht, W.: Attributing ozone to $\mathrm{NO}_{\mathrm{x}}$ emissions: Implications for climate mitigation measures, Atmos. Environ., 59, 102-107, 2012.

Jaffe, D. A. and Widger, N. L.: Ozone production from wildfires: A critical review, Atmos. Environ., 51, 1-10, 2012.

Jallais, S.: Etude expérimentale et modélisation de l'oxydation d'hydrocarbures légers, PhD Thesis ENSMA, Poitiers, 2001.

Kee, R. J., Rupley, F. M., and Miller, J. A.: CHEMKIN-II: A FORTRAN Chemical Kinetics Package for the Analysis of Gas-Phase Chemical Kinetics, Report No. SAND 89-8009, Sandia National Laboratories, Livermore, CA, USA, 1989.

Leroy, V., Leoni, E., and Santoni, P. A.: Reduced mechanism for the combustion of evolved gases in forest fires, Combust. Flame, 154, 410-433, 2008.

Mebust, A. K., Russell, A. R., Hudman, R. C., Valin, L. C., and Cohen, R. C.: Characterization of wildfire NOx emissions using MODIS fire radiative power and OMI tropospheric $\mathrm{NO}_{2}$ columns, Atmos. Chem. Phys., 11, 5839-5851, doi:10.5194/acp11-5839-2011, 2011.
Mendiara, T. and Glarborg, P.: Ammonia chemistry in oxy-fuel combustion of methane, Combust. Flame, 156, 1937-1949, 2009.

Miller, J. and Bowman, C.: Mechanism and modeling of nitrogen chemistry in combustion, Prog. Energ. Combust., 15, 287-338, 1989.

Miranda, A. I.: An integrated numerical system to estimate air quality effects of forest fires, Int. J. Wildland Fire, 13, 1-10, 2004.

Mitchell, J. W. and Tarbell, J. M.: A kinetic model of nitric oxide formation during pulverized coal combustion. AICHE J., 28, 302-311, 1982.

Morvan, D. and Dupuy, J. L.: Modelling the propagation of a wildfire through a Mediterranean shrub using a multiphase Formulation, Combust. Flame, 138, 199-210, 2004.

Ottomar, R., Miranda, A. I., and Sandberg, D.: Characterizing sources of emissions from wildland fires, Chapter 3, in: Wildland Fires and Air Pollution, Developments in Environmental Science, edited by: Bytnerowicz, A., Arbaugh, M., Riebau, A., and Andersen. C., vol 8. Elsevier, Amsterdam, ISBN 978-0-08055609-3, 2009.

Pérez-Ramirez, Y., Santoni, P. A., Darabiha, N., Leroy-Cancellieri, V., and Leoni, E.: A Global Kinetic Model for the Combustion of the Evolved Gases in Wildland Fires, Combust. Sci. Technol., 184, 1380-1394, 2012.

Rogaume, T., Koulidiati, J., Richard, F., Jabouille, F., and Torero, J.: A model of the chemical pathways leading to $\mathrm{NO}_{\mathrm{x}}$ formation during combustion of mixtures of cellulosic and plastic materials, Int. J. Therm. Sci., 45, 359-366, 2006.

Salzmann, R. and Nussbaumer, T.: Fuel Staging for NOx Reduction in Biomass Combustion: Experiments and Modeling, Energ. Fuel., 15, 575-582, 2001.

Santoni, P. A.: Introduction à la problématique des feux de forêt. Ecole de combustion, Ecole thématique du CNRS, Fréjus, France, 2008.

Santoni, P. A., Simeoni, A., Rossi, J. L., Bosseur, F., Morandini, F., Silvani, X., Balbi, J. H., Cancellieri, D., and Rossi, L.: Instrumentation of wildland fire: Characterization of a fire spreading through a Mediterranean shrub. Fire Safety J., 41, 171-184, 2006.

Strada, S., Mari, C., Filippi, J.-B., and Bosseur, F.: Wildfire and the atmosphere: Modelling the chemical and dynamic interactions at the regional scale, Atmos. Environ., 51, 234-249, 2012.

Sullivan, A. L.: A review of wildland fire spread modelling, 1990present. 1. Physical and quasi-physical models, Int. J. Wildland Fire, 18, 349-368, 2009.

Sullivan, A. L and Ball, R.: Thermal decomposition and combustion chemistry of cellulosic biomass, Atmos. Environ., 47, 133-141, 2012.

Sullivan, N., Jensen, A., Glarborg, P., Day, M. S., Grcar, J. F., Bell, J. B., Pope, C. J., and Kee, R. J.: Ammonia conversion and NOx formation in laminar coflowing nonpremixed methane-air flames, Combust. Flame, 131, 285-298, 2002.

Tihay, V., Santoni, P. A., Simeoni, A., Garo, J. P., and Vantelon, J. P.: Skeletal and global mechanisms for the combustion of gases released by crushed forest fuels, Combust. Flame, 156, 15651575, 2009a.

Tihay, V., Simeoni, A., Santoni, P. A., Rossi, L., Garo, J. P., and Vantelon, J. P.: Experimental Study of Laminar Flames Obtained 
by the Homogenization of Three Forest Fuels, Int. J. Therm. Sci., 48, 488-501, 2009b.

Weissinger, A., Fleckl, T., and Obernberger, I.: In situ FT-IR spectroscopic investigations of species from biomass fuels in a laboratory-scale combustor: the release of nitrogenous species, Combust. Flame, 137, 403-417, 2004.
Zhou, H., Jensen, A., Glarborg, P., and Kavaliauskas, A.: Formation and reduction of nitric oxide in fixed-bed combustion of straw, Fuel, 85, 705-716, 2006. 